\title{
DETERMINATION OF HLB VALUES OF SOME NONIONIC SURFACTANTS AND THEIR MIXTURES
}

\author{
RÉKA KOTHENCZ ${ }^{\text {** }}$, ROLAND NAGYa ${ }^{\mathrm{a}}$ LÁSZLÓ BARTHA $^{\mathrm{a}}$
}

\begin{abstract}
Advanced analytical and impact assessment methods are needed for the development of modern surfactants, so the composition, the effect and other properties of surfactants are examined by analytical tools which may be suitable for the quality testing of the raw materials, the intermediates and the final products. The HLB values of non-ionic surfactants and their mixtures were determined by three different methods: theoretical HLB based on the chemical structure and the given HLB of surfactants, the Greenwald method and an improved, titrimetric method. Our aim was to investigate if the new method to determine the water number and HLB value is suitable for this type of commercial surfactants and their mixtures. The particle size and the turbidity of micelles formed in surfactant solutions were also measured and evaluated.
\end{abstract}

Keywords: surfactant, surfactant mixtures, theoretical $H L B$ value, experimental HLB value

\section{INTRODUCTION}

Surfactants in science and industry are widely used, ranging from primary production processes such as the recovery and purification of raw materials in the mining and petroleum industries, to enhancing the quality of finished products such as paints, cosmetics, pharmaceuticals, and foods. Polyethoxylated ester (POE) non-ionics, such as Tween product family, are generally excellent dispersing agents [1]. Sodium dodecylbenzenesulfonate (SDBS) is an anionic surfactant which is the major component of laundry detergents [2].

\footnotetext{
a University of Pannonia, Institutional Department of MOL Hydrocarbon and Coal Processing, 10 Egyetem str., HU-8200, Veszprém, Hungary

*Corresponding author: kothenczr@almos.uni-pannon.hu
} 
The capacity of the emulsification, the solubility and other surfactant properties depend on the HLB value of a given non-ionic surfactant which information is necessary for its practical application. The HLB (hydrophiliclipophilic balance) concept was introduced by Griffin [3]. The HLB of an emulsifier is a number which expresses the mass ratio of water-soluble and oil-soluble groups in the surfactant molecule. The HLB value can be a critical factor in the development of new emulsions and in surfactant synthesis. The number of experiments can be reduced during the formulation screening stage and can be used as an important parameter for quality control [4].

The present work aimed to investigate if the new method to determine the water number and HLB value is suitable for this type of commercial surfactants and their mixtures. The difference between the HLB values determined by different methods was examined, the particle size and the turbidity of their aqueous solution was also investigated.

\section{RESULTS AND DISCUSSION}

\section{Investigation of non-ionic surfactants}

The HLB of POE surfactants was determined by conventional analytical method (Greenwald et al) [6] and by our improved method then it was compared with the HLB given by the manufacturer (Table 1, Figure 1). No information was provided about the HLB measurement method of the manufacturer.

Table1. The HLB values of Tween non-ionic surfactants

\begin{tabular}{|c|c|c|c|}
\hline $\begin{array}{c}\text { Product } \\
\text { name }\end{array}$ & $\begin{array}{c}\text { HLB } \\
\text { (given by } \\
\text { manufacturer) }\end{array}$ & $\begin{array}{c}\text { HLB } \\
\text { (Greenwald) }\end{array}$ & $\begin{array}{c}\text { HLB } \\
\text { (improved } \\
\text { method) }\end{array}$ \\
\hline Tween 20 & 16.7 & 20.4 & 16.0 \\
\hline Tween 40 & 15.6 & 18.9 & 16.0 \\
\hline Tween 60 & 14.9 & 16.1 & 14.7 \\
\hline Tween 80 & 15.0 & 16.6 & 14.4 \\
\hline Tween 85 & 11.0 & 14.9 & 10.6 \\
\hline
\end{tabular}

The HLB values determined by our new developed method approximates better the given HLB values, than the HLB values of Greenwald method [7].

The hydrodynamic size of each surfactant was determined by dynamic light scattering method and the turbidity by fiber-optic spectrophotometer (Table 2). 
The average size of the surfactant micelles was between $11.4 \mathrm{~nm}$ and $90.4 \mathrm{~nm}$. It can be explained by the different micelle formation because of the diverse structure of surfactants.

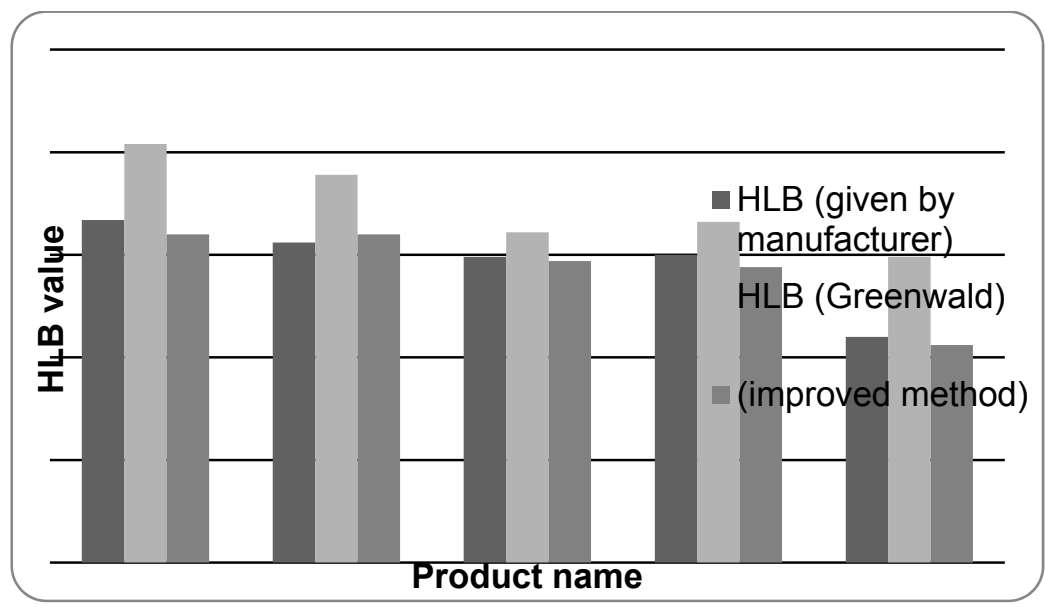

Figure 1. Difference between the HLB values determined by different methods

Table 2. Hydrodynamic size and turbidity of POE and SDBS surfactant solutions

\begin{tabular}{|c|c|c|}
\hline $\begin{array}{c}\text { Product } \\
\text { name }\end{array}$ & $\begin{array}{c}\text { Hydrodynamic } \\
\text { size (nm) }\end{array}$ & $\begin{array}{c}\text { Turbidity } \\
(\mathbf{\%})\end{array}$ \\
\hline Tween 20 & 44.3 & 62 \\
\hline Tween 40 & 61.4 & 58 \\
\hline Tween 60 & 56.2 & 52 \\
\hline Tween 80 & 11.4 & 7 \\
\hline Tween 85 & 90.4 & 77 \\
\hline
\end{tabular}

\section{Investigation of surfactant mixtures}

The surfactants are usually applied as surfactant mixtures [10] thus our aim was to determine their HLB value by our improved, titrimetric method described in the previous chapter.

No experimental results were published about the determination of HLB values of surfactant mixtures by Greenwald et al [11].

The HLB of surfactant mixtures was determined as follows (Table 3):

- weighted regarding the mixing ration (50 w/w\% anionic, $50 \mathrm{w} / \mathrm{w} \%$ non-ionic surfactant), the following HLB values were considered for the calculation $[12,13]$ : 
- anionic surfactant: HLB calculated by the chemical structure,

o non-ionic surfactant: HLB given by the manufacturer.

- conventional analytical method (Greenwald method),

- the improved method.

The HLB value of SDBS was 19.9 and it was calculated based on its chemical structure.

Table 3. The HLB values of surfactant mixtures

\begin{tabular}{|c|c|c|c|}
\hline $\begin{array}{c}\text { Surfactant } \\
\text { mixture }\end{array}$ & $\begin{array}{c}\text { HLB } \\
\text { (theoretical) }\end{array}$ & $\begin{array}{c}\text { HLB } \\
\text { (Greenwald) }\end{array}$ & $\begin{array}{c}\text { HLB } \\
\text { (improved method) }\end{array}$ \\
\hline T-1 & 18.25 & 19.70 & 18.25 \\
\hline T-2 & 17.70 & 19.20 & 17.58 \\
\hline T-3 & 17.35 & 19.10 & 17.41 \\
\hline T-4 & 17.40 & 19.30 & 18.00 \\
\hline T-5 & 15.40 & 16.90 & 15.20 \\
\hline
\end{tabular}

It was found that our improved method is suitable to determine also the HLB of this type of surfactant mixtures.

The difference between HLB values determined by different methods is shown in Figure 2.

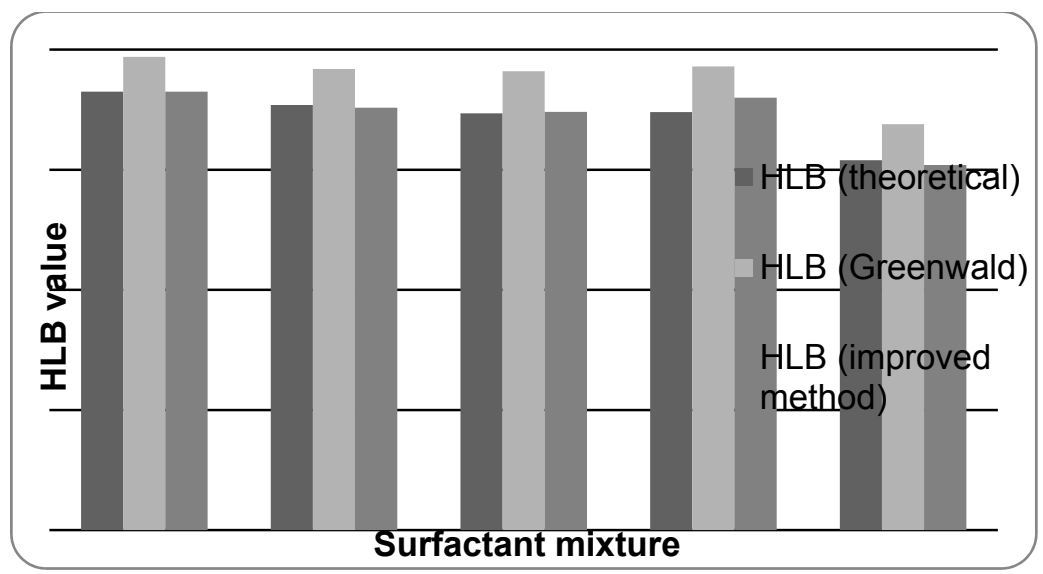

Figure 2. The difference between HLB values of surfactant mixtures determined by different methods

The HLB measured by our improved method approximates better the calculated theoretical HLB based on the chemical structure. Adding SDBS to the surfactant mixtures has resulted higher HLB values, thus the solubility in water has increased. 
The average size of the surfactant micelles was between $123 \mathrm{~nm}$ and $910 \mathrm{~nm}$ and the turbidity was between $7-57 \%$. The higher HLB value of surfactant mixtures has shown lower turbidity. However based on the measured particle size it was obtained that the formed micelles are bigger which require more detailed structural analysis.

Table 4. The particle size of the micelles and the turbidity of surfactant mixture solutions

\begin{tabular}{|c|c|c|}
\hline Surfactant mixture & Particle size (nm) & Turbidity (\%) \\
\hline T-1 & 384 & 52 \\
\hline T-2 & 624 & 48 \\
\hline T-3 & 684 & 53 \\
\hline T-4 & 910 & 7 \\
\hline-5 & 123 & 57 \\
\hline
\end{tabular}

No correlation was found between the HLB value and the average particle size. The HLB value of the surfactant mixture can provide information about the hydrophilic or lipophilic nature but not about the ability of association or the colloidal properties of the surfactant mixture. Thus the HLB can be applied for the classification of surfactants which is important in terms of use.

\section{CONCLUSIONS}

The HLB values of non-ionic surfactants and their mixtures, the turbidity of their aqueous solution and the average size of micelles formed in aqueous solution of non-ionic surfactants and their mixtures were analyzed. The new experimental results can be summarized as follows.

- Based on the experimental data a more accurate method was developed for the determination of HLB which is applicable to POE type non-ionic surfactants.

- The improved method is suitable for the determination of HLB of this type of surfactant mixtures.

- In both case (nonionic and anionic surfactant alone or in their mixtures) the HLB value determined by our method approximates better the HLB value calculated by chemical structure.

- The particle size of surfactant association of the components not depends on the HLB value, but depends on the structure of surfactants. Further developments could contribute significantly to the formulation of the surfactant mixtures. 


\section{EXPERIMENTAL}

\section{Materials}

Polyethoxylated sorbitan esters, environmentally friendly non-ionic surfactant family marketed under the Tween product name were used in the measurements. A polyethoxylated monoester of 3,6-sorbitan is represented in figure 3. POEs are hydrophilic in nature and are soluble or dispersible in water and dilute solutions of electrolytes [5]. The chemical identity of Tween products is shown in Table1.

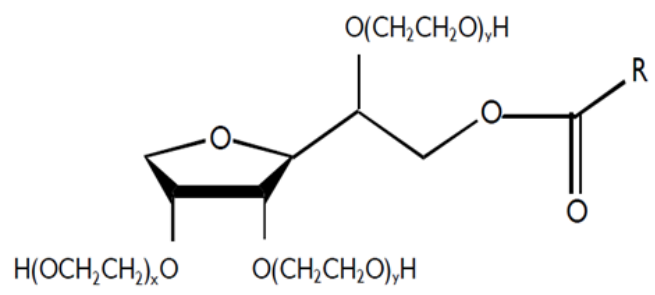

Figure 3. Chemical structure of a polyethoxylated monoester (R: alkyl group of fatty acid where $(x+y)$ is the total number of moles of ethylene oxide)

Table 5. Chemical identity of Tween products

\begin{tabular}{|c|c|}
\hline Product name & Chemical identity \\
\hline Tween 20 & PEG-20 sorbitan monolaurate \\
\hline Tween 40 & PEG-20 sorbitan monopalmitate \\
\hline Tween 60 & PEG-20 sorbitan monostearate \\
\hline Tween 80 & PEG-20 sorbitan monooleate \\
\hline Tween 85 & PEG-20 sorbitan trioleate \\
\hline
\end{tabular}

Sodium dodecylbenzenesulfonate (SDBS) is a member of the linear alkylbenzenesulfonates, the dodecyl group is unbranched. This dodecyl chain is attached at the 4-position of the benzenesulfonate group.

The composition of the surfactant mixtures is shown in Table 6. The mixtures contained $50 \mathrm{w} / \mathrm{w} \%$ of non-ionic and $50 \mathrm{w} / \mathrm{w} \%$ of anionic surfactants.

For preparing the surfactant solutions, the surfactants were dissolved in distilled water in $1 \mathrm{w} / \mathrm{w} \%$ of total concentration. 


\section{Methods}

\section{Water Number and HLB determination}

The method developed by Greenwald, Brown and Fineman [6] is suitable to determine the hydrophilic-lipophilic nature of the surfactants. It can provide information about the possible effectiveness of the emulsifiers.

Table 6. The composition of the surfactant mixtures

\begin{tabular}{|c|c|c|}
\hline $\begin{array}{c}\text { Surfactant } \\
\text { mixture }\end{array}$ & $\begin{array}{c}\text { Non-ionic surfactant } \\
\text { component }\end{array}$ & $\begin{array}{c}\text { Anionic surfactant } \\
\text { component }\end{array}$ \\
\hline T-1 & Tween 20 & SDBS \\
\hline T-2 & Tween 40 & SDBS \\
\hline T-3 & Tween 60 & SDBS \\
\hline T-4 & Tween 80 & SDBS \\
\hline T-5 & Tween 85 & SDBS \\
\hline
\end{tabular}

The surfactant is dissolved in benzene-dioxane mixture and the solution is titrated with distilled water until its permanent turbidity according to Greenwald et al [6]. Our method was developed to avoid the use of the highly toxic benzene. In our new process of sample preparation the test materials are dissolved in the mixture of cyclohexane-dioxane (with 4\% cyclohexane content). The distilled water is added to the solution of surfactant until it becomes permanently cloudy and the transmittance cannot be decreased radically by the further addition of water. The transmittance is measured by fiber-optic spectrophotometer. The current transmittance values are represented as a function of distilled water volumes. The equivalence point of the obtained curve is the volume which corresponds to the Water Number (WN) of the surfactant [6]. The HLB value can be calculated from the Water Number, the equation of the improved method was created by linear regression.

Equation 1 can be applicable for non-ionic surfactants [7] and Equation 2 for surfactant mixtures [8].

$$
\begin{aligned}
& \mathrm{HLB}=\frac{\mathrm{WN}}{0.6524}-0.6339 \\
& \mathrm{HLB}=\frac{\mathrm{WN}}{1.206}-10.5
\end{aligned}
$$

\section{Solubility in water}

$1 \mathrm{w} / \mathrm{w} \%$ of surfactant is dissolved in distilled water. The turbidity is measured by spectrophotometer. The solubility in water is characterized by the transmittance $(\mathrm{T})$ value ( $0 \%$ completely cloudy, $100 \%$ transparent). The turbidity of the diluted surfactants was calculated as [9]:

$$
\text { Turbidity }=100-\mathrm{T}(\%)
$$




\section{Particle size analysis}

The average particle size and the distribution of the surfactants were measured by dynamic light scattering using Malvern Zetasizer Nano ZS instrument. The hydrodynamic radius determined by photon correlation spectroscopy (i. e. dynamic light scattering) and is estimated from the particles' diffusivity using the Stokes-Einstein relationship (Equation 4). The peak values of particle diameter $(\mathrm{nm})$ for the different samples were obtained as an average of the data. In this work particle size means the size of surfactant associations formed in the aqueous solution.

where:

$$
\mathrm{D}_{0}=\frac{\mathrm{kT}}{3 \pi \eta \mathrm{d}}
$$

$\mathrm{D}_{0}$ : diffusion coefficient

k: Boltzmann constant

T: temperature

$\eta$ : dynamic viscosity

d: particle diameter

\section{REFERENCES}

1. M.J. Rosen, J.T. Kunjappu, „Surfactants and interfacial phenomena”, John Wiley and Sons, 2012, chapter 1.

2. D. Myers, „Surfactant science and technology”, Wiley-Interscience, 2006, chapter 2.

3. C.W. Griffin, Journal of the Society of Cosmetic Chemists, 1949, 1(5), 311.

4. C.P. Fernandes, M.P. Mascarenhas, F.M. Zibetti, B.G. Lima, R.P.R.F. Oliveira, L. Rocha, D.Q Falcao, Revista Brasiliera de Farmacognosia 2013, 23(1), 108.

5. "The HLB SYSTEM, a time-saving guide to emulsifier selection”, ICI Americas Inc., 1994.

6. P. Becher, "Emulsions: Theory and Practice", Reinhold Publishing Corp., 1965, chapter 6.

7. R. Kothencz, R. Nagy, L. Bartha, Nano, Bio and Green- Technologies for a Sustainable Future, $16^{\text {th }}$ International Multidisciplinary Scientific Geoconference SGEM, 2016, 6(3), 45.

8. R. Nagy, R. Kothencz, L. Bartha, XXII. International Conference on Chemistry, Timisoara, Romania, 2016, 102.

9. R. Nagy, R. Kothencz, R. Sallai, L. Bartha, International Journal of Scientific and Engineering Research, 2015, 6(3), 580.

10. S.P. Current, US5110487, 1992.

11. X. Guo, Z. Rong, X. Ying, Journal of Colloid and Interface Science, 2006, 298, 441.

12. "HLB \& Emulsification, Description of Hydrophile, Lipophile Balance and use of HLB in Producing Emulsions", Akzo Nobel Surface Chemistry LLC, 2008.

13. R.C. Pasquali, M.P. Taurozzi, C. Bregni, International Journal of Pharmaceutics, 2008, 356, 44. 